\title{
A PERCEPÇÃO DO SURDO SOBRE O ATENDIMENTO NOS SERVIÇOS DE SAÚDE
}

\author{
Hindhiara Freire Pires*, Maria Antonieta Pereira Tigre Almeida** \\ Autora para correspondência: Hindhiara Freire Pires - hyndhyarap@gmail.com \\ * Discente do Curso de Graduação em Enfermagem na Faculdade Independente do Nordeste \\ ** Docente da Faculdade Independente do Nordeste, Vitória da Conquista - BA. Intérprete de Libras
}

\section{Resumo}

Os objetivos desse estudo foram identificar os métodos de comunicação utilizados para atendimento aos Surdos nos serviços de saúde, investigar como se estabelece o vínculo entre os Surdos e os profissionais da saúde e verificar as percepções dos Surdos quanto ao acolhimento existente nos serviços de saúde. Metodologia: Trata-se de um estudo descritivo-exploratório de abordagem qualitativa, em que participaram 26 pessoas Surdas, as quais foram entrevistadas usando-se LIBRAS. As interações foram transcritas em um questionário, mantendo-se a construção gramatical característica das expressões dessas pessoas. Resultados e discussão: O Surdo não tem alcançado uma comunicação efetiva Durante o atendimento de saúde, no qual experimenta sentimentos negativos. Os relatos dos participantes do estudo salientaram dificuldades para um atendimento de saúde devidamente correto e qualificado, como: ausência e bloqueio de comunicação, um dos grandes obstáculos que prejudica um possível vínculo entre profissionais de saúde e os Surdos, e que consequentemente comprometem o atendimento, a necessidade de intermediação pelo acompanhante. Relataram também o desejo de haver um profissional interprete e o despreparo dos profissionais que os atendem. Considerações finais: Se faz necessário que os profissionais utilizem de aspectos supras segmentais para que os Surdos possam ter um suporte no atendimento, portanto sugere-se a necessidade de implantar LIBRAS como disciplina curricular, não sendo optativa, mas obrigatória em todos os cursos de graduação da área de saúde. Diante de relatos verídicos evidenciou-se que os profissionais de saúde estão despreparados para o atendimento de pacientes Surdos.

Palavras-chave: LIBRAS; Atendimento; Comunicação; Surdez. 


\title{
THE PERCEPTION OF DEAF PATIENTS REGARDING HEALTH CARE SERVICES
}

\begin{abstract}
The objectives of this study were to identify the communication methods used to care for the Deaf in health services, investigate how to establish the link between the Deaf and the health professionals and verify the perceptions of the Deaf on in the way they are treated in the health services. Methodology: This is a descriptive and exploratory qualitative study, involving 26 deaf people, who were interviewed using sign language. The interactions were transcribed in a questionnaire, keeping the characteristic grammatical construction expression of these persons. Results and discussion: The Deaf persons do not achieve effective communication during the health care, so they end up experiencing negative feelings. The reports of the study participants pointed out difficulties in order to obtain qualified health care services such as: absence of and disrupted communication, one of the biggest obstacles which jeopardize a possible link between health professionals and the deaf, and consequently compromises the care, the necessity to intermediation by the companion. Also reported the desire to have in the health services a professional interpreter and the lack of ability of the professionals who treat them. Final considerations: It is necessary that the professionals use the super segmental aspects for the deaf may have a support in care, therefore suggests the necessity to employ sign language as a curricular component, in spite of being optional, but obligatory in all healthcare undergraduate courses. In linght of the true accounts there is evidence that health professionals are unprepared to care for deaf patients.
\end{abstract}

Keywords: Sign Language; Care; Communication; Deafness.

\section{INTRODUÇÃO}

As pessoas que procuram os serviços de saúde buscam, além de acolhimento, relações solidárias e de confiança com os profissionais para poder resolver seu problema de saúde. O indivíduo Surdo, ao buscar atendimento na Unidade de Saúde, encontra como bloqueio, a sua comunicação com a equipe. Por não fazer uso da língua verbal, o mesmo se comunica através da Língua de Brasileira de Sinais (LIBRAS), sendo desconhecida pelos profissionais de saúde, na maioria das vezes, e com a ausência de intérpretes no local, a assistência para com o Surdo, deixa de ser humanizada e eficaz.

Comunicar-se é algo do convívio no qual compartilhamos emoções, ideias, sentimentos e mensagens o que pode induzir comportamento das pessoas que, por sua vez, reagirão a partir de seus valores, história de vida, cultura e suas crenças. ${ }^{(1)}$
$\mathrm{Na}$ assistência de saúde, é necessário relacionar-se e comunicar-se de modo cuidadoso e responsável, procurando traduzir, entender, compreender e perceber o significado da mensagem que o paciente envia, consequentemente identificando suas necessidades. $^{(2)}$

O Decreto n. 5626, de 22 de dezembro de 2005, que regulamentou a Lei 10.436/02, também denominada Lei de Libras, trata dos aspectos relativos à inclusão de Libras nos cursos superiores, à formação de professores para o ensino de Libras, à formação de tradutores e intérpretes de Libras, à atuação do Serviço Único de Saúde - SUS, à capacitação de servidores públicos para o uso da Libras ou sua interpretação e à dotação orçamentária para garantir as ações previstas no Decreto $5626 / 05 .{ }^{(3)}$ 
Os Surdos, bem como os outros indivíduos, necessitam de atendimento em saúde, não obrigatoriamente ligado à surdez propriamente dita. Os profissionais de saúde enfrentam dificuldades de comunicação ao prestar assistência a pacientes com déficit auditivo. ${ }^{(1)}$

A Língua de Sinais (LS) encontra-se em todos os continentes, porém não possui uma estrutura universal, mas exibem estrutura gramatical diversificada. A característica espaço-visual é sua particularidade, onde o individuo Surdo recebe a informação através dos olhos e sua produção, sua transmissão é cometida pelas mãos, no espaço. A Linguística reconhece que a LS possui uma estrutura tão complexa como as línguas faladas, o que permite a atribuição ao conceito de línguas naturais. (4)

Geralmente o encontro clínico entre o profissional da saúde e o cidadão Surdo ocorre fora dos padrões previstos na rotina de qualquer profissional. A situação se torna limitada para o profissional tanto quanto para o paciente o que prejudica a comunicação, consequentemente a criação de vínculos a ser estabelecidos entre ambos. A gravidade da situação torna-se maior se for levado em conta o fato de que a Língua de Sinais (LS) na maioria, esmagadora, das vezes é desconhecida pelos profissionais de saúde. Alguns imaginam que a solução estaria na solicitação do intérprete da LS como intermediário, deixando subentendido à necessidade de inclusão de uma terceira pessoa nesta relação para que se efetive a comunicação. ${ }^{(5)}$

Visto que há uma dificuldade de comunicação dos profissionais de saúde com o paciente Surdo, o presente estudo tem por objetivos, analisar a assistência prestada aos Surdos quando estes procuram os serviços de saúde; identificar os métodos de comunicação utilizados para atendimento aos Surdos nos serviços de saúde; investigar como se estabe- lece o vínculo entre os Surdos e os profissionais da saúde; e verificar as percepções dos Surdos quanto ao acolhimento existente nos serviços de saúde.

\section{METODOLOGIA}

Trata-se de um estudo descritivo-exploratório de abordagem qualitativa. A coleta foi realizada em janeiro de 2016 através de entrevista semiestruturada em uma escola pública de Vitória da Conquista, Centro-Sul da Bahia. A amostra foi constituída por 26 estudantes surdos, com diagnóstico de surdez comprovada, com idade entre 18 e 30 anos. O pesquisador, com auxílio de um questionário previamente construído, realizou a entrevista. As indagações pertinentes foram intermediadas pelo intérprete, o qual, ao obter as respostas, as dizia em voz alta para captação de um gravador comum. Posteriormente, estas respostas gravadas foram transcritas para o Microsoft Word 2010, e analisadas por meio de Análise de Conteúdo (AC). O presente projeto foi aprovado pelo Comitê de Ética em Pesquisa da Faculdade Independente do Nordeste - FAINOR, sob parecer $n^{\circ}$ 1.415.031. Antes da coleta de dados, os participantes foram esclarecidos sobre os objetivos da pesquisa e assinaram o Termo de Consentimento Livre e Esclarecido (TCLE). Todas as etapas para coleta de dados foram intermediadas por um intérprete de LIBRAS.

\section{RESULTADOS E DISCUSSÃO}

A partir da tabela 1, percebe-se uma predominância do número de participantes do gênero feminino $(61,5 \%)$. Quanto à idade, os participantes possuem uma faixa etária que varia de 18 a 30 anos.

Tabela 1 - Caracterização dos participantes da pesquisa quanto ao gênero

\begin{tabular}{|c|c|c|}
\hline GÊNERO & $N$ & $\%$ \\
\hline Feminino & 16 & 61,5 \\
\hline Masculino & 10 & 38,5 \\
\hline Total & 26 & 100 \\
\hline
\end{tabular}

Fonte: elaboração do autor (2016). 
Essa predominância do sexo feminino, a não ser maioria entre o sexo masculino entre os participantes, não possui relevância se a pesquisa tratasse de dados expressivos, pois não há estudos que indiquem ou comprovem a prevalência maior de surdez no sexo feminino do que no sexo masculino, e vice-versa.
Em relação a qual(is) o(s) meio(s) de comunicação os participantes utilizam como recurso para se comunicarem com os profissionais nas unidades de saúde, todos $(100,0 \%)$ disseram que se comunicam através da escrita.

Tabela 2 - Recursos utilizados como meio comunicação com os profissionais de saúde

\begin{tabular}{lcc}
\hline \multicolumn{1}{c}{ Meios de ComUnicaÇão } & UtilizaM & $\%$ \\
\hline Mímica & - & - \\
Desenho & - & - \\
Escrita & 26 & 100 \\
Libras & - & - \\
Acompanhante & 26 & 100 \\
\hline Total & 26 & 100 \\
\hline
\end{tabular}

Fonte: elaboração do autor (2016).

Depois de falar, escrever é um dos primeiros meios de comunicação que se aprende. Mas e para quem não fala? E os Surdos onde se encaixam? Numa era tão avançada onde à inclusão social é um dos pilares de acessibilidade há, ainda, uma deficiência em não conhecer a Língua de Sinais que é a língua oficial do Surdo, havendo essa necessidade a escrita torna-se um importante instrumento de comunicação entre os Surdos e ouvintes.

Sobre a necessidade de outros meios de comunicação todos responderam que vão com acompanhantes para as consultas. Considerando as respostas dos participantes, percebe-se que os Surdos, na generalidade, precisam de pessoas que interpretem e traduzam suas emissões para os profissionais e vice-versa, aflorando, assim, a necessidade de haver intermédio de uma terceira pessoa. Essa figura do intermediador caracteriza-se na família, amigos e, raramente, com intérprete profissional. Personagens como avó, amigos, irmãos, namorados, mãe entre outros apareceram nesse contexto, porém a figura materna se destacou, incontestavelmente, aparecendo em vinte e dois da totalidade de vinte e seis participantes. O Surdo não encontra oportunidade de se expressar e nem de expor as suas dúvidas na consulta, mantendo o cargo do acompanhante a responsabilidade de explicar ao profissional os problemas de saúde que este apresenta, sendo também a pessoa quem recebe as orientações. Além disso, a presença do acompanhante retira do Surdo o direito da individualidade necessária para a sua exposição, muitas vezes passam por despercebidas à angústia e as dificuldades que só o próprio Surdo sente, quando é transferida para os familiares a responsabilidade da comunicação.(6)

Em conformidade com a análise de dados categorial temática, foi possível estabelecer 5 categorias para expor os resultados da pesquisa:

\section{CATEGORIA 1: PENSAMENTOS E SENTIMENTOS DO SURDO DIANTE O ATENDIMENTO NOS SERVIÇOS DE SAÚDE}

Todos os participantes relataram ter apresentado um misto de sentimentos, dentre eles: tristeza, raiva e decepção, diante dos fatos de não serem 
compreendidos pelos profissionais de saúde que não sabem se comunicar com eles. Nas respostas à entrevista, percebe-se a indignação do Surdo, o que não se dá somente pela falta de comunicação, mas associado ao desinteresse dos profissionais com o mesmo nas consultas. Essa falta de interação entre o profissional e o paciente é evidenciada nas falas a seguir.

Sinto muita tristeza e a certeza que o Surdo é discriminado. Médicos e enfermeiros não se importam com os Surdos, só nos atendem se estivermos com acompanhante. (Inf. 12)

Fico triste, pois o medico e o enfermeiro não fala com o Surdo. Vou para o hospital com muito medo. (Inf. 21)

É triste, tenho 21 anos e vou ao médico com minha mãe porque ninguém entende o que eu falo. Acho feio. (Inf.11)

Muita decepção. Como cidadã não tenho direito garantido de sigilo medico. (Inf. 14)

A partir do pressuposto que a sociedade atual tenha acesso à informação preponderantemente através da comunicação oral/auditiva, o bloqueio de comunicação entre Surdos e profissionais da saúde instala-se como um dos grandes obstáculos da comunidade Surda, quando procura serviços de saúde. O indivíduo Surdo precisa ser assistido de forma global, respeitadas suas crenças, seus valores e diferenças. ${ }^{(7)}$

A língua usada pelos Surdos, língua de sinais, tem gramática e vocabulários díspar da língua portuguesa, o que os torna fluentes em LIBRAS e não em português. Ainda que não exista diálogo ou uma comunicação entre paciente-profissional é importante que o profissional saiba interpretar os gestos, expressões faciais e corporais do Surdo. Quando o Surdo busca atendimento nos serviços de saúde e está sintomático e/ou com alguns sinais clínicos de doença, torna-se fácil para o profissional identificar o que está ocorrendo. Porém, quando assin- tomático ou em doenças sem causa aparente, em que se faz necessário coletar, de modo abrangente, a história do paciente, a situação se complicada. ${ }^{(1)}$

O Surdo pode sim utilizar gestos e expressões que não pertencem à LIBRAS, mas que são entendidas universalmente por Surdos, como expressões de dor, apontando o local e definindo o tipo de dor. O individuo que é alfabetizado em português pode escrever o que quiser, porém, como já foi dito, a construção gramatical é diferente do Surdo. Desse modo, o profissional deve pacientemente tentar entender o que o Surdo quer expressar a fim de evitar que estes não procurem os serviços de saúde, apenas, em situações emergenciais, mas tenham acessibilidade com universalidade, equidade e integralidade como preconiza os princípios doutrinários do SUS.(1)

\section{CATEGORIA 2: DIRECIONAMENTO DAS PERGUNTAS DURANTE A CONSULTA E SENTIMENTO DA PESSOA SURDA EM RELAÇÃO À ESSA SITUAÇÃO}

Um problema pertinente, relatado por todos os Surdos durante a entrevista foi que os profissionais de saúde direcionam as perguntas aos acompanhantes, o que desperta insegurança e indignação dos mesmos.

Sempre fazem as perguntas ao acompanhante. Parece que o médico quer que a consulta acabe logo para o Surdo sair da sua sala. (Inf. o1)

Pergunta só a minha acompanhante. Só penso se minha mãe falou tudo que sinto ao medico e o que ele falou para minha mãe. (Inf. O2)

Só fala com meu acompanhante. Não olham pra gente e quando fala ol hando para a pessoa surda é assustado. (Inf. ०8)

Só conversa com minha acompanhante. Penso em quem está na consulta? Porque ele só conversa com minha mãe. (Inf. 17) 
Além disso, a insegurança pode surgir pelo fato do profissional não entender os problemas de saúde do Surdo, podendo gerar um diagnóstico ineficaz.

Ele pergunta a minha acompanhante. O medico falou com minha mãe e eu continuei com duvida sinto muita dor e não sei se é dengue, zika ou chicungunya. (Inf. o6)

Eles só falam com o acompanhante. O médico conversa com minha mãe e me examina depois perguntando a ela o que estou dizendo. Fico muito triste. (Inf. 13)

Quando não há comunicação entre Surdo-profissional o atendimento fica voltado para o acompanhante, consequentemente prejudicando a interação do paciente com o profissional, sendo assim, essa falta de interação provoca insegurança e constrangimento da parte do Surdo.

Atualmente no Brasil apesar de existirem campanhas recentes como a intitulada "Iguais na $\mathrm{Di}$ ferença", criada pela Secretaria Especial dos Direitos Humanos, políticas e leis como a Lei Federal $n$. 10.436/02 regulamentada pelo Decreto n. 5.626/05, a inclusão e a independência do Surdo ao procurarem serviços de saúde, e outros serviços, ainda é baixa, devido à grande escassez de informações sobre si e seus direitos por parte dos profissionais que os atendem. Essa situação afeta principalmente as consultas médicas e de enfermagem, pois os Surdos apresentam restrições frente a uma sociedade ainda precária no conhecimento de sua cultura, o que leva a família a sempre acompanhá-los.

As barreiras de comunicação, não apenas por parte do Surdo ao procurar os serviços de saúde, mas também da parte dos profissionais que os atendem, são alarmantes. Quando não existe a possibilidade de haver uma comunicação efetiva, não há como contribuir com o paciente a resolver seus problemas e reduzir conflitos pelo déficit que estes profissionais apresentam em relação a LIBRAS. ${ }^{(8)}$

\section{CATEGORIA 3: INTÉRPRETE DE LIBRAS DURANTE AS CONSULTAS}

Dos 26 participantes, a maioria relata que os profissionais não utilizam LIBRAS para se comunicar, apenas 02 comentaram sobre as recentes mudanças no estado de São Paulo, relacionado ao atendimento ao Surdo.

Nenhum profissional sabe utilizar LIBRAS aqui em Vitória da Conquista, mas vi pelo Jornal Nacional que em São Paulo já tem. (Inf. O1)

Em Vitória da Conquista ninguém usou LIBRAS comigo, mas vi que São Paulo já tem pelo Jornal Nacional. (Inf. O2)

Os outros $\mathrm{O} 2$ participantes conheceram uma fonoaudióloga e uma técnica em enfermagem que sabia LIBRAS.

Foi muito legal. Ela ajudou o médico a me atender. (Inf. o1)

Quando percebi que ela sabia falar LIBRAS, me senti muito feliz porque meu atendimento seria feito bem. (Inf. 15)

É sabido da necessidade de haver intérpretes de LIBRAS nos serviços de saúde, e outros. A Lei $n$. 10.436 , de 24 de abril de 2002, regulamenta o uso da LIBRAS, e estabeleça que as instituições públicas e empresas concessionárias de serviços públicos de assistência à saúde devem garantir atendimento e tratamento adequado aos Surdos, os profissionais desconhecem a linguagem deste e não há intérpretes disponíveis nos serviços de saúde. Apesar da LIBRAS e outros recursos de expressão a ela associados sejam reconhecidos como métodos legais de comunicação e expressão, não se faz obrigatório que os profissionais saibam ou entendam LIBRAS. ${ }^{(8)}$

Em Setembro de 2015 o Jornal Nacional revelou que o estado de São Paulo possui aproximadamente dois milhões de Surdos. Para melhorar a qualidade de vida desses pacientes, que sempre se sen- 
tem excluídos ao procurarem os serviços de saúde, os hospitais do estado passaram a ter gente treinada para traduzir a língua de sinais durante as consultas. ${ }^{(8)}$

Mais que isso, entrou em funcionamento a Central de Intérpretes de LIBRAS (CIL) onde há três tipos de atendimentos: $1^{\circ}$ ) Atendimento "in loco", onde o usuário solicita que um intérprete de LIBRAS ou guia-intérprete se desloque até o serviço público em que ele precise de atendimento; $2^{\circ}$ ) Atendimento presencial, em que o solicitante se dirige até o endereço da CIL para que um intérprete o auxilie, por exemplo, em uma ligação telefônica que ele precise fazer para um órgão público; $3^{\circ}$ ) Funcionará em um futuro bem próximo onde CIL prestará também atendimento virtual, que está em processo final de implementação. Tal reportagem foi mencionada por dois participantes da pesquisa e esta poderia servir de influência para implementação em outros Estados do País. No nordeste, especificamente na Bahia, a presença de um interprete ainda não é uma realidade. ${ }^{(9)}$

\section{CATEGORIA 4: ACESSO AOS SERVIÇOS DE SAÚDE NA CIDADE DE VITÓRIA DA CONQUISTA}

A partir dessa categoria emergiram 02 subcategorias de avaliação dos atendimentos de saúde ao Surdo.

Subcategoria 1: Percepção do Surdo de como deveria ocorrer, da recepção ao atendimento médico, o acolhimento nesses serviços de saúde

Ainda que seja uma realidade distante e, talvez, inacessível para a maioria dos Surdos, a figura do intérprete entre os participantes, talvez, fosse a solução. Em geral, 19 participantes acham que $o$ atendimento melhoraria se houvesse um interprete de LIBRAS para auxiliar médicos e enfermeiros. $E$ foi-lhes indagado a seguinte pergunta: Como você acha que deveria ser os atendimentos nos serviços de saúde?
O médico saber Libras, mas isso é utopia. Então o interprete é uma forma possível. (Inf. ०8)

Com interprete. Deveria haver uma central de interpretes para quando o médico fosse atender um paciente Surdo ligasse e solicitasse o serviço. (Inf. 16)

Com interprete. Melhoraria na ética profissional, pois o Surdo não pode tirar duvidas com o acompanhante. (Inf. 17)

Com interprete, para saber e ajudar mais sobre o problema de saúde. (Inf. 18)

É imprescindível, portanto, que a presença do interprete trata-se de uma demanda urgente. $O$ intérprete não teria apenas responsabilidades de tradução, mas participaria ativamente de toda conjuntura do atendimento, afinal a sua presença tornaria possível, ao paciente e o profissional de saúde, alcançar o objetivo desse encontro: compreensão. Ter um intérprete de LIBRAS desmitificaria o fato de que o sujeito Surdo quando procura atendimento, médico e/ou de enfermagem, só pode escrever para se comunicar.

A presença de um intérprete nas consultas aprimora a execução do atendimento em saúde, o que não garante que contribui com grande peso na qualidade do serviço. ${ }^{(10)}$ Sugere-se que os profissionais de saúde não só aprendam a LIBRAS, mas aprimorem e aprofundem o desempenho na troca de informações com o Surdo através da Língua Brasileira de Sinais. ${ }^{(11)}$

Subcategoria 2: A procura do serviço de saúde pelo Surdo sem acompanhante

Na maioria, esmagadora, das vezes os Surdos precisam de pessoas que traduzam suas expressões e emissões para os profissionais e vice-versa, tornando perceptível, a necessidade de mediar à comunicação. Dos 26 participantes da pesquisa, apenas O4 já procuraram os serviços de saúde sozinhos, e O2 relataram experiências constrangedoras. 
Fui sozinha e foi muito difícil pra mim. O médico se irritou, meu Deus eu só sou Surda. (Inf. 21)

Fui fazer uma audiometria sozinha. O médico e a enfermeira ficou olhando pra mim com cara de assustados. (Inf. 12)

E o1 dos participantes relatou que não procura atendimento médico.

Não vou a médico, compro remédio por conta própria. (Inf.10)

Os únicos desejos dos Surdos são de serem respeitados e compreendidos quando procuram, não apenas, os serviços de saúde, mas também em qualquer situação em que haja necessidade de interação com outras pessoas. O fato é que ainda vivenciamos a exclusão na assistência à saúde oferecida para essa classe.

Os profissionais de saúde tem como dever aprender e reconhecer a língua de sinais como forma de interação do Surdo com o mundo, o que resultaria não apenas no combate às patologias, mas não diminuição dos obstáculos que insistem em interferir em uma comunicação adequada. (7)

A escola possui papel de grande peso na formação dos indivíduos e seus aspectos futuros. Em um futuro próximo, a LIBRAS tende a ganhar dimensão maior, o art. $3^{\circ}$ do Decreto 5.626 de dezembro de 2005, diz que LIBRAS será inserida como "disciplina curricular obrigatória" nos cursos de formação de professores para o exercício do magistério, em nível médio e superior, e nos cursos de Fonoaudiologia, de instituições de ensino, públicas e privadas". Para os demais cursos de educação superior é introduzida como disciplina optativa, mas se faz necessário obrigatoriedade em todos os cursos de graduação relacionados a saúde, visto que o despreparo dos profissionais da área compromete, eminentemente, a eficácia do atendimento. Sendo assim o atendimento se tornará justo e igualitário, na qual as diferenças serão respeitadas e, os atendimentos nos serviços de saúde serão de grande qualidade para dos Surdos. ${ }^{(3)}$
CATEGORIA 5: SENTIMENTO DO SURDO APÓS ATENDIMENTO, COM MÉDICO E/ OU ENFERMEIRO, EM RELAÇÃO AO TRATAMENTO/EXAMES/SITUAÇÃO CLÍNICA

A ausência do diálogo entre paciente-profissional o atendimento é dificultado, agravando ainda mais essa situação. A realidade é que quando os Surdos tentam se comunicar sem a intermediação do seu acompanhante não há escuta dos profissionais de saúde. Na generalidade, os participantes afirmaram sair com dúvidas e medo do atendimento com os profissionais de saúde, as falas demonstram que o processo de comunicação gera medo no Surdo, pois eles não saem inseguros do atendimento que fora recebido.

Estou com muitas duvidas. Fiquei doente por causa desse mosquito, vou ficar bom? Sinto muitas dores, minha mãe falou que não tem remédio. Não sei se é verdade. O médico conversou com ela, será que vou para o hospital? (Inf. o6)

Fico com muitas duvidas. Os resultados dos exames não entendo e minha família também não entende. Muitas duvidas sempre, por isso vou muitas vezes ao medico por que $\tilde{n}$ resolve o problema $e$ nunca sabem o que tenho. (Inf. 14)

Já tive problemas e fui ao médico tomar uma injeção para alergia, fiquei muito empolada, com frio e tremendo muito (reação anafilática), tomei outro remédio para alergia sem o medico dizer nada. Ele não sabia o que eu tinha, fiquei com medo de morrer. (Inf. 22)

Sinto muita duvida. Não quero remédio, não vou tomar por que não sei o que eu tenho. (Inf. 23)

Saber se comunicar com o Surdo é indicio de promoção de uma assistência humanizada e propicia para esses pacientes. Os participantes, em generalidade, se demonstraram frustrados, tristes, duvidosos e insatisfeitos com os atendimen- 
tos prestados e precariamente recebidos na cidade de Vitoria da Conquista. Duvidas e medo foram os sentimentos mais expostos pelos participantes, o que estão relacionados a não comunicação e a falta de compreensão das informações transmitidas pelos profissionais, como o uso de medicamentos e diagnósticos de doenças.

Não compreender instruções prescritas e/ou estipuladas pelos profissionais de saúde pode ter como consequência interpretações errôneas o que prejudica à saúde do Surdo e, consequentemente, The dá inseguridade em relação à sua cura. ${ }^{(12)}$

\section{CONCLUSÃO}

O Surdo não é capaz de se comunicar com os ouvintes através da língua falada, dessa forma, a pessoa surda não consegue manter uma comunicação satisfatória com os ouvintes à sua volta. A presente pesquisa proporciona uma concepção e óptica sobre a realidade vivenciada no atendimento em saúde ao Surdo. Os relatos dos participantes do estudo salientaram dificuldades para um atendimento de saúde devidamente correto e qualificado, como: ausência de comunicação efetiva entre profissional de saúde e paciente Surdo a necessidade de intermediação pelo acompanhante, o despreparo dos profissionais que os atendem, da recepção até o ápice das orientações ministradas ao paciente no tratamento, cuidados e prevenção. Esses problemas relatados evidenciam a existência de um bloqueio de comunicação que prejudica um possível vinculo entre profissionais de saúde e os Surdos, que consequentemente compromete 0 atendimento. Neste contexto, presume-se que a presença de um intérprete de LIBRAS facilitaria o processo de comunicação, entretanto, não contribuiria integralmente para a inclusão do Surdo. Portanto, verifica-se a necessidade de implantar LIBRAS como disciplina curricular, não sendo optativa, mas obrigatória em, todos os cursos de graduação da área de saúde.

\section{REFERÊNCIAS}

1. Cardoso AH, Rodrigues KG, Bachion MM. Percepção da pessoa com surdez severa e/ou profunda acerca do processo de comunicação durante seu atendimento de saúde. Rev Lat Am Enferm. 2006;14(4):553-560.

2. Pagliuca LMF, Fiuza NLG, Reboucas CB de A. Aspectos da comunicação da enfermeira com o deficiente auditivo. Rev Esc Enferm USP. 2007;41(3): 411-418.

3. Brasil. Lei $n^{\circ} 10.436$, de 24 de abril de 2002. Dispõe sobre a Língua Brasileira de Sinais Libras. Diário Oficial União, Brasília, 23 dez. 2005 [acesso em 2015 set O1]. Disponível em: http://www.planalto.gov.br/ccivil_O3/_ ato20042006/2005/decreto/d5626.htm

4. Quadros RM de, Karnopp L. Língua de sinais brasileira: estudos lingüísticos. Porto Alegre: ArtMed; 2004.

5. Aguiar FS, Marcucci RMB. Uso da Linguagem Brasileira de Sinais na comunicação enfermeiro-paciente portador de deficiência auditiva. Rev Enferm UNISA.2009;10(2):144-8.

6. Silva RNA et al. Assistência ao Surdo na Atenção Primária: concepções de profissionais. COFEN. Maranhão. 2014 [2016 jun 14]. Disponível em: http://apps.cofen.gov.br/cbcenf/ sistemainscricoes/arquivosTrabalhos/165684. E13.T11218.D9AP.pdf

7. Chaveiro N, Barbosa MA, Porto CC. Revisão de literatura sobre $o$ atendimento ao paciente surdo pelos profissionais da saúde. Rev Esc Enferm USP. 2008 [acesso em 2015 nov 19];42(3):578-83. Disponível em: http://www. scielo.br/scielo.php?pid=\$00806234200800 0300023\&script=sci_arttext

8. Abreu JC de, Freitas JMRF, Rocha LLV. $A$ percepção dos surdos em relação ao sistema de comunicação das Unidades de Atenção Primária à Saúde - UAPS. Brazilian Journal of Surgery and Clinical Research. 2014/2015;9(1):6-11.

9. Central de Interpretação de Libras começa a funcionar no Centro de SP. Jornal Nacional. São Paulo, 22 set. 2015. Disponível em: http:// gl.globo.com/sao-paulo/noticia/2015/O9/ 
central-de-interpretacao-de-libras-comecafuncionar-no-centro-de-sp.html

10. Acioli MB et. al. Princípios de universalidade, integralidade e equidade em um serviço de atenção à saúde auditiva. Ciênc Saúde Coletiva. 2014 [2016 mar 15]; 19(7): 2179-2188. Disponível em: http://dx.doi.org/10.1590/141381232014197.09392013
11. Lopes KS et al. Percepção da equipe de enfermagem acerca da assistência prestada ao deficiente auditivo. Revista Enfermagem Integrada. 2009 [2015 maio 03]; 2(1):165175. Disponível em: http://www.unilestemg. br/enfermagemintegrada/artigo/v2/Herina_ oliveira_Keylla_lopes_e_Neila_pinto.pdf

12. Castro SS et. al. Acessibilidade aos serviços de saúde por pessoas com deficiência. Rev Saúde Pública. 2011 [2016 abr 2]; 45(1):99-105. Disponível em: <http:// www.scielo.br/scielo.php?pid=SOO34$89102011000100011 \&$ script=sci_arttext 